\title{
Thermal Processing Effects on the Chemical Constituent and Antioxidant Activity of Okara Extracts Using Subcritical Water Extraction
}

\author{
Hongyi Sun, Xi Yuan, Zhenya Zhang, Xin Su, and Min Shi 1 \\ Graduate School of Life and Environmental Sciences, University of Tsukuba, Ibaraki, Japan \\ Correspondence should be addressed to Min Shi; shimin0816@gmail.com
}

Received 23 April 2018; Accepted 28 June 2018; Published 1 August 2018

Academic Editor: Beatriz Oliveira

Copyright (c) 2018 Hongyi Sun et al. This is an open access article distributed under the Creative Commons Attribution License, which permits unrestricted use, distribution, and reproduction in any medium, provided the original work is properly cited.

\begin{abstract}
Subcritical water extraction (SWE) has been employed for the extraction of bioactive compounds from plant materials with costeffectiveness, less consuming time, and environmental sustainability. To explore the effects of thermal processing during SWE, total organic content (TOC), total sugar, polysaccharides, total phenolic content (TPC), total flavonoid content (TFC), and antioxidant activity (ABTS and DPPH assays) of eight aqueous extracts have been quantitatively investigated. The results indicated that elevated temperatures indeed resulted in significant changes in the constituents and antioxidant activities of okara extracts. Among them, the extract obtained at $220^{\circ} \mathrm{C}$ exhibited the highest total phenolic, flavonoid content, DPPH (2,2diphenyl-1-picrylhydrazyl) radical-scavenging activity, and ABTS [2,2'-azino-bis(3-ethylbenzothiazoline-6-sulfonate)] radicalscavenging activity. However, phenolic compounds were destroyed after the treatment above $230^{\circ} \mathrm{C}$, suggesting that any polymer processing is improper to undertake at higher than this value to achieve the high antioxidant activity. Moreover, a significant positive correlation between TPC or TFC and antioxidant capacity (DPPH and ABTS) values was detected.
\end{abstract}

\section{Introduction}

Okara is rich in bioactive compounds including dietary fiber, protein, polysaccharides, and phenolic compounds, many of which have been claimed to contribute to the antioxidant activity due to their redox properties derived from various possible mechanisms: free radical-scavenging activity, transition-metal-chelating activity, and/or singlet-oxygenquenching capacity [1]. For instance, phenolic compounds play an important role in stabilizing lipid peroxidation and inhibiting various types of oxidizing enzymes [2]. Nevertheless, the differences in the structures and substitutions may influence the phenoxyl radical stability and impair the antioxidant properties.

Subcritical water extraction (SWE) is defined as hot water at temperatures ranging between $100^{\circ} \mathrm{C}$ and $374^{\circ} \mathrm{C}$ under high pressure to maintain water in the liquid state [3]. As one of an environmentally friendly and efficient technique, it has been a wide range of applications, such as extraction, hydrolysis, and wet oxidation of organic compounds $[4,5]$. Elevated temperatures can modify the dielectric constant and ionization constant of water, resulting in the possibility of tuning its polarity and accelerating hydrolysis, thereby obtaining organic compounds instead of using organic solvents during food industry processing [6].

It is well known that heating extraction is an essential processing procedure, especially during SWE processing, which is attributed to the oxidation, thermal degradation, and leaching of bioactive compounds from fresh vegetables [7]. Depending upon the morphology and nutritional properties of raw materials, different heating conditions, such as heating duration and temperatures, have either positive or negative effects on the antioxidant properties of vegetables [8].

However, no information is available on the effects of thermal treatments on bioactive compounds and antioxidant activity in okara under subcritical water conditions. Therefore, the objective of this study was to investigate the 
effects of different temperatures under subcritical water extraction conditions on a range of potentially health-related chemical constituents and antioxidant capacities, in order to evaluate the potential of SWE for the production of high bioactive extracts from okara.

\section{Materials and Methods}

2.1. Chemicals and Standard Solutions. Ascorbic acid, Folin-Ciocalteu reagent, ethanol, sodium carbonate, gallic acid, sodium nitrite, aluminium nitrate, sodium hydroxide, disodium hydrogen phosphate, potassium persulphate, sodium dihydrogen phosphate, phenol, and D-glucose were purchased from Wako Pure Chemical (Osaka, Japan). 1,1-diphenyl-2-picrylhydrazyl radical (DPPH), 2,2'-azinobis(3-ethylbenzothiazoline-6-sulfonic acid) (ABTS) were purchased from Sigma-Aldrich, Inc. (Saint Louis, MO, USA). All the other chemical reagents were of analytical grade.

2.2. Sample Preparation. Okara (78.8\% moisture content) was purchased from Inamoto Co., Ltd. (Tsukuba, Japan). Residual water was removed by drying at $60^{\circ} \mathrm{C}$ for $5 \mathrm{~h}$, ground in a high-speed disintegrator (IFM-800, IWATANI, JAPAN) to obtain a fine powder $(250 \mu \mathrm{m})$, and then refluxed with $85 \%$ ethanol at $70^{\circ} \mathrm{C}$ for $4 \mathrm{~h}$ to defat, deactivate enzymes, and remove interference components. The residue was thermally dried at $50^{\circ} \mathrm{C}$ and vacuum packed to decrease lipid oxidation.

2.3. Extraction Procedure. A schematic diagram of the semicontinuous SWE unit is shown in Figure 1. Subcritical water extraction was performed in a $200 \mathrm{~mL}$ SUS-316 stainless steel tube reactor (MMS-200, OMLABO, JAPAN) with the maximum operating pressure of $20 \mathrm{MPa}$ and temperature of $300^{\circ} \mathrm{C}$. The extraction system consists of an extraction vessel (i.d. $38.5 \mathrm{~mm} \times 197 \mathrm{~mm}$ ) covered with a heating jacket, a Bourdon tube pressure gauge, a pressure release valve, and a temperature sensor connected with a temperature controller by the thermocouple to monitor the real-time temperature. In a typical run, $1.0 \mathrm{~g}$ of pretreated okara powder was loaded inside the extraction reactor. After adding a fixed liquid-solid ratio of $30 \mathrm{~mL} / \mathrm{g}$, the vessel was electrically heated to each specific temperature, which generally took less than $8 \mathrm{~min}$. The extraction process then lasted $10 \mathrm{~min}$ at the required temperature $\left(160-230^{\circ} \mathrm{C}\right)$. The extracts were centrifuged at $3600 \mathrm{rpm}$ for $10 \mathrm{~min}$ and separated from the soluble liquid portion through a filter paper (Whatman number 1). All of the supernatant were stored at $4^{\circ} \mathrm{C}$ in the dark before use.

2.4. Determination of Total Organic Carbon (TOC). TOC was measured by a TOC analyzer (TOC-VCSN, Shimadzu, Japan) after the samples being centrifuged and filtrated through $0.45 \mu \mathrm{m}$ membrane. More details on the determination of TOC have previously been reported [9].

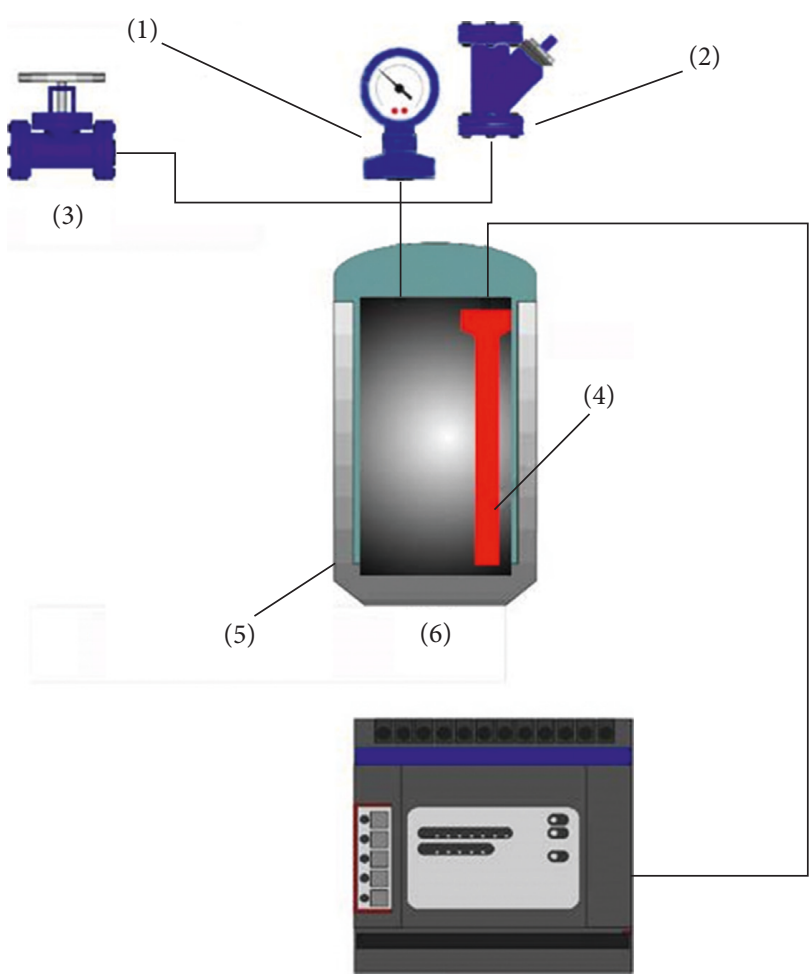

(7)

FIgURE 1: Experimental schematic diagram of the subcritical water system for crude polysaccharide production from okara. (1) Pressure gauge, (2) safety head, (3) pressure release valve, (4) temperature sensor, (5) insulation jacket, (6) SWT reactor, and (7) temperature controller and thermocouple.

2.5. Determination of Total Sugar. The total sugar was determined by the phenol-sulfuric acid method with certain modifications [10]. The color reaction was initiated by mixing $1 \mathrm{~mL}$ of solution with $0.5 \mathrm{~mL}$ of a $5 \%$ phenol solution and $2.5 \mathrm{~mL}$ of concentrated sulfuric acid, and the reaction mixture was incubated in a boiling water bath for $15 \mathrm{~min}$. After cooling to room temperature, the optical density (O. D.) of the mixture was determined at $490 \mathrm{~nm}$ and the total carbohydrate content was calculated with D-glucose as a standard. The results were expressed as milligram of glucose equivalent per gram of okara [11].

2.6. Determination of Polysaccharides. The filtrate was precipitated by adding dehydrated ethanol to a final concentration of $80 \%(\mathrm{v} / \mathrm{v})$ and stored at $4^{\circ} \mathrm{C}$ for $12 \mathrm{~h}$. The precipitate was harvested as crude polysaccharides after centrifugation at $7500 \mathrm{rpm}$ for $15 \mathrm{~min}$ and washed triple times using dehydrated ethanol. After being redissolved in ultrapure water, the aqueous solution was subjected to remove proteins by using the Sevag reagent [12], dialyzed with deionized water for $72 \mathrm{~h}$, and concentrated under reduced pressure. Finally, the polysaccharide product was collected after lyophilization. Polysaccharide content was assayed using the phenol-sulfuric acid method [13]. All the results were expressed as $\mathrm{mg}$ of glucose equivalent per $\mathrm{g}$ of the pretreated okara. 
2.7. Analysis of Total Phenolic Compounds. Total phenolic content (TPC) was determined on the basis of the FolinCiocalteu colorimetric method [14]. The sample $(0.5 \mathrm{~mL})$ and $2 \mathrm{~mL}$ of sodium carbonate $(75 \mathrm{~g} / \mathrm{L})$ were added to $2.5 \mathrm{~mL}$ of $10 \%(w / v)$ Folin-Ciocalteu reagent. After $30 \mathrm{~min}$ of reaction at room temperature (intermittent shaking for color development), the absorbance was measured at $765 \mathrm{~nm}$. The TPC was determined from the linear equation of a standard curve prepared with gallic acid.

2.8. Analysis of Total Flavonoid Compounds. The total flavonoid content (TFC) in extract was measured by a colorimetric assay [15]. The extract $(5 \mathrm{~mL})$ was added to a $10 \mathrm{~mL}$ flask, and then $5 \% \mathrm{NaNO}_{2}$ solution $(0.3 \mathrm{~mL})$ was added. After mixed well, the solution was allowed to stand for $6 \mathrm{~min}$ at room temperature; $5 \% \mathrm{Al}\left(\mathrm{NO}_{3}\right)_{3}$ solution $(0.3 \mathrm{~mL})$ was added to the flask, mixed well, and kept for $6 \mathrm{~min}$ at room temperature. At last $4 \% \mathrm{NaOH}$ solution $(4.4 \mathrm{~mL})$ was added, mixed well, and kept for $12 \mathrm{~min}$ at room temperature. Absorbance was read on a UV spectrophotometer at $510 \mathrm{~nm}$, and the total flavonoid contents (\%) were estimated using calibration curves. Total flavonoid content in samples was calculated from a calibration curve $\left(R^{2}=0.999\right)$ using rutin and expressed as mg of rutin equivalent (RE) per $g$ of dry weight.

\subsection{Antioxidant Activities}

2.9.1. DPPH Radical-Scavenging Activity Assay. DPPH radical-scavenging activity of extractions was evaluated according to a literature procedure with a slight modification [13]. Aliquots $(0.5 \mathrm{~mL})$ of various concentrations $(0.3125-$ $10.00 \mathrm{mg} / \mathrm{mL})$ of extracts were mixed with $3 \mathrm{~mL}(25 \mu \mathrm{g} / \mathrm{mL})$ of a $\mathrm{MeOH}$ solution of $\mathrm{DPPH}$ and then were shaken vigorously and allowed to stand in the dark for $30 \mathrm{~min}$. The absorbance was measured with a spectrophotometer at $517 \mathrm{~nm}$ against a blank. Decrease of the DPPH solution absorbance indicated an increase of the DPPH radicalscavenging activity. Ascorbic acid was used as positive controls. DPPH radical-scavenging activity was calculated according to the following equation:

$$
\text { scavenging activity }(\%)=\left(1-\frac{A_{1}}{A_{0}}\right) \times 100 \% \text {, }
$$

where $A_{0}$ is the absorbance without samples and $A_{1}$ is the absorbance containing the samples.

Results were expressed in millimole ( $\mathrm{mM}$ ) ascorbic acid equivalent (AAE) per $1 \mathrm{~g}$ of a sample on a dry weight basis.

2.9.2. ABTS Radical-Scavenging Activity Assay. ABTS radical-scavenging activity was measured using the methods with some modifications [16]. ABTS was dissolved in distilled water at a final concentration of $7.0 \mathrm{mM}$ and mixed with a potassium persulphate solution at a final concentration of $2.45 \mathrm{mM}$. The mixture was conserved in the dark at ambient temperature for $12-16 \mathrm{~h}$ before use. For individual sample experiment, prepared $\mathrm{ABTS}^{++}$solution was diluted with $0.01 \mathrm{M}$ phosphate buffer saline (PBS, $\mathrm{pH} 7.4$ ) to achieve its absorbance within $0.70 \pm 0.02$ at $734 \mathrm{~nm}$ wavelength. And then a constant volume $(0.15 \mathrm{~mL})$ of various concentrations of samples $(0.3125-10.00 \mathrm{mg} / \mathrm{mL})$ was reacted with $2.85 \mathrm{~mL}$ of $\mathrm{ABTS}^{+}$solution by mixing vigorously. Eventually, the absorbance was measured at $734 \mathrm{~nm}$ after incubation at ambient temperature for $10 \mathrm{~min}$. Ascorbic acid was used as positive controls. The scavenging activity of the ABTS free radicals was calculated using the following equation:

$$
\begin{aligned}
\text { scavenging activity }(\%)= & {\left[1-\frac{\left(A_{1}-A_{2}\right)}{\left(A_{3}-A_{4}\right)}\right] } \\
& \times 100 \%,
\end{aligned}
$$

where $A_{1}$ is the absorbance of ABTS solution + sample, $A_{2}$ is the absorbance of potassium persulphate + sample, $A_{3}$ is the absorbance of ABTS solution + distilled water, and $A_{4}$ is the absorbance of potassium persulphate + distilled water.

Results were expressed in millimole ( $\mathrm{mM}$ ) ascorbic acid equivalent (AAE) per $1 \mathrm{~g}$ of a sample on a dry weight basis.

2.10. Statistical Analysis. The data obtained in this study were expressed as the mean of three replicate determinations plus or minus the standard deviation (SD). The content of total phenolic content was calculated as mean $\pm \mathrm{SD}(n=3)$ and expressed as mg gallic acid equivalents (GAEs)/g dry weight. The Pearson correlation coefficient $(R)$ and pvalue were used to show correlations and their significances (SPSS 19.0 for Windows, SPSS Inc. IL, USA). Probability values of $p<0.05$ and $p<0.01$ were considered to be statistically significant and extremely significant, respectively.

\section{Results and Discussions}

\subsection{Extraction Yields}

3.1.1. General. As other processing steps like milling, grinding, and homogenization, extraction can recover and isolate phytochemicals from plant materials and is important for obtaining extracts with acceptable yields and strong antioxidant activity [17]. Generally, extraction efficiency is associated with the chemical nature of phytochemicals, the extraction method used, sample particle size, the solvent used, as well as the presence of interfering substances [18]. Besides, the yield of extraction depends on the solvent with varying polarity, $\mathrm{pH}$, temperature, extraction time, and composition of the sample. Among these influential factors, extraction temperature is one of the crucial parameters, especially under the subcritical condition.

In the current study, a reaction time was $10 \mathrm{~min}$ and a liquid-solid ratio was $30 \mathrm{~mL} / \mathrm{g}$ based on previous optimal extraction conditions using response surface methodology [19]. The various extractions from okara at different temperatures were presented in Table 1 . The results revealed a considerable diversity in the chemical constituents in the extracts investigated in the present study. For TOC, it was kept relatively stable until $180^{\circ} \mathrm{C}$, which produced the highest value of $30.00 \pm 0.73 \%$ and then sharply decreased to 
TABLe 1: Chemical constituents and antioxidant activities of different okara extracts by using SWE.

\begin{tabular}{|c|c|c|c|c|c|c|c|}
\hline $\begin{array}{l}\text { Temperature } \\
\left({ }^{\circ} \mathrm{C}\right)\end{array}$ & TOC (\%) & $\begin{array}{l}\text { Total sugar } \\
\text { (mg.GE/g) }\end{array}$ & $\begin{array}{c}\text { Polysaccharides } \\
\text { (mg.GE/g) }\end{array}$ & $\begin{array}{c}\text { TPC } \\
(\mathrm{mg} \cdot \mathrm{GAE} / \mathrm{g})\end{array}$ & $\begin{array}{c}\text { TFC } \\
(\mathrm{mg} \cdot \mathrm{RE} / \mathrm{g})\end{array}$ & $\begin{array}{c}\text { DPPH } \\
(\mathrm{mM} \cdot \mathrm{AAE} / \mathrm{g})\end{array}$ & $\begin{array}{c}\text { ABTS } \\
(\mathrm{mM} \cdot \mathrm{AAE} / \mathrm{g})\end{array}$ \\
\hline 160 & $29.83 \pm 0.75$ & $210.36 \pm 4.35$ & $145.61 \pm 3.09$ & $23.32 \pm 0.14$ & $15.60 \pm 0.87$ & $0.85 \pm 0.14$ & $31.54 \pm 0.73$ \\
\hline 170 & $28.27 \pm 0.79$ & $174.02 \pm 2.41$ & $92.41 \pm 0.23$ & $27.12 \pm 0.37$ & $18.27 \pm 0.19$ & $3.39 \pm 0.27$ & $45.00 \pm 2.30$ \\
\hline 180 & $30.00 \pm 0.73$ & $163.77 \pm 1.42$ & $61.86 \pm 2.98$ & $39.05 \pm 0.46$ & $20.31 \pm 0.40$ & $7.31 \pm 0.35$ & $73.77 \pm 1.15$ \\
\hline 190 & $20.64 \pm 0.73$ & $112.56 \pm 6.14$ & $48.86 \pm 1.40$ & $50.50 \pm 0.54$ & $28.12 \pm 0.88$ & $18.73 \pm 1.15$ & $103.28 \pm 2.41$ \\
\hline 200 & $21.73 \pm 0.35$ & $89.16 \pm 1.81$ & $19.01 \pm 1.14$ & $67.25 \pm 0.73$ & $49.00 \pm 1.40$ & $23.75 \pm 0.36$ & $126.37 \pm 0.88$ \\
\hline 210 & $22.17 \pm 0.25$ & $61.08 \pm 2.09$ & $3.13 \pm 0.045$ & $71.14 \pm 0.54$ & $58.12 \pm 0.64$ & $38.67 \pm 1.14$ & $156.19 \pm 3.47$ \\
\hline 220 & $20.86 \pm 0.20$ & $39.09 \pm 0.93$ & $0.54 \pm 0.0091$ & $76.18 \pm 0.45$ & $66.12 \pm 0.69$ & $43.43 \pm 0.58$ & $177.12 \pm 8.77$ \\
\hline 230 & $20.30 \pm 0.23$ & $22.83 \pm 0.44$ & $0.30 \pm 0.014$ & $70.82 \pm 0.65$ & $65.91 \pm 0.66$ & $41.83 \pm 1.53$ & $169.61 \pm 9.70$ \\
\hline
\end{tabular}

$20.64 \pm 0.73 \%$, possibly owing to a weak hydrolysis reaction, pyrolysis, and gasification of the organic compounds [3]. The trend of total sugar was similar to that of TOC. With the increasing temperatures, total sugar reduced continuously from $210.36 \pm 4.35 \mathrm{mg} \cdot \mathrm{GE} / \mathrm{g}$ to $22.83 \pm$ $0.44 \mathrm{mg} \cdot \mathrm{GE} / \mathrm{g}$. There was a wide range of variations in total polysaccharides, from $0.30 \mathrm{mg} \cdot \mathrm{GA} / \mathrm{g}$ to $145.61 \mathrm{mg} \cdot \mathrm{GA} / \mathrm{g}$. The results were consistent with the fact that total sugars of the aqueous phase comprise mixtures of poly-, oligo-, di-, and monosaccharides [20].

3.1.2. Total Phenolic Content. Phenolic compounds have inhibitory effects on mutagenesis and carcinogenesis in humans when ingested up to $1 \mathrm{~g}$ daily from a diet rich in fruits and vegetables [21]. The interests of phenolics are increasing in the food industry because they retard oxidative degradation of lipids and thereby improve the quality and nutritional value of food [22]. The total phenolic content of diverse extracts in this study was determined based on the aforementioned reagent method. TPC values were calculated from the gallic acid standard calibration curve $y=0.0056 x-0.0003$ with $R^{2}=0.9995$, where $x$ is the absorbance and $y$ is the concentration of gallic acid equivalents expressed as mg GAE/g. Significant differences were found for TPC among the extracts at various subcritical temperatures. The TPC of various aqueous extracts was in the range of $23.32 \pm 0.14 \mathrm{mg} \cdot \mathrm{GAE} / \mathrm{g}$ to $76.18 \pm 0.45 \mathrm{mg} \cdot \mathrm{GAE} / \mathrm{g}$ (increased by 3.27 folds) under subcritical conditions (Table 1). The cleaving of the esterified and glycosylated bond or the formation of the Maillard reaction during the heating process may be responsible for the increase in total phenolics after heating $[8,23]$. However, when the heating temperature rose to $230^{\circ} \mathrm{C}$, a slight decrease $(70.82 \pm 0.65 \mathrm{mg} \cdot \mathrm{GAE} / \mathrm{g})$ occurred, mainly because of accelerated interaction decomposition of target products under the elevated temperature. And the results are in good agreement with the published results related to the total phenolic content of canola meal achieved by subcritical water technology [24].

3.1.3. Total Flavonoid Content. Flavonoids are the naturally occurring polyphenols representing one of the most prevalent classes of compounds in vegetables, nuts, fruits, and beverages such as coffee, tea, and red wine [25]. TFC values were calculated from rutin standard calibration curve $y=0.0012 x+0.0027$ with $R^{2}=0.992$, where $x$ is the absorbance and $y$ is the concentration of rutin equivalents expressed as mg.RE/g. The TFC of okara extracted at different temperatures in this study is shown in Table 1. An increasing trend of TFC in first seven extracts was found as the temperature elevated, whereas there was a moderate decrease in the TFC when the temperature reached to $230^{\circ} \mathrm{C}$. The total flavonoid contents varied from $15.60 \pm 0.87\left(160^{\circ} \mathrm{C}\right)$ to $66.12 \pm 0.69 \mathrm{mg} \cdot \mathrm{RE} / \mathrm{g}\left(220^{\circ} \mathrm{C}\right)$ with the difference of $4.24-$ fold in the initial flavonoid contents. The decrease in the total flavonoid at a higher temperature could be attributed to the degradation of flavonoids, which possibly depends on the structure of particular flavonoids [8]. Our results are in agreement with the findings of Ioku et al. [26] who found that total flavonoid content increased after heating at a certain temperature and magnitude of time, whereas too much exposure to severe conditions reduced the content of total flavonoid content. Moreover, in most fruits and vegetables, flavonoids contain glycosidic bonds and exist as dimers and oligomers, and the industrial processing such as heating or boiling results in the formation of monomers by the hydrolysis of glycosidic bonds [27].

\subsection{Antioxidant Activities}

3.2.1. DPPH Radical-Scavenging Activity. Since different trends have been found in numerous antioxidant activity assays, it is of necessity to evaluate and compare the antioxidant capacity of extracts by means of multiple assays rather than one single test. Hence, the total antioxidant activity of extracts in this study needed to be measured using the DPPH assay and the ABTS assay, respectively.

$\mathrm{DPPH}$ radical is a stable free radical with a characteristic absorption maximum at $517 \mathrm{~nm}$ [28]. The DPPH radical-scavenging activity assay is sensitive enough to accommodate samples in a short period of time and detect active ingredients at low concentrations [29]. The DPPH scavenging radical effects of the eight different aqueous extracts from okara and standard antioxidant (ascorbic acid) were compared and shown in Figure 2. In this study, ascorbic acid showed DPPH radical-scavenging activity of $97.30 \pm 0.12 \%$ at the initial concentration of $0.3125 \mathrm{mg} / \mathrm{mL}$, exhibiting excellent scavenging ability on DPPH radicals. And altered concentrations of all the SWE extracts $(0.3125$, $0.625,1.25,2.5,5$, and $10 \mathrm{mg} / \mathrm{mL}$ ) showed DPPH scavenging activities in a dose-dependent manner. As shown in Table 1, all aqueous extracts on the DPPH assay followed an 
ascending the order of $160^{\circ} \mathrm{C}<170^{\circ} \mathrm{C}<180^{\circ} \mathrm{C}<190^{\circ} \mathrm{C}<200^{\circ} \mathrm{C}$ $<210^{\circ} \mathrm{C}<230^{\circ} \mathrm{C}<220^{\circ} \mathrm{C}$. And it was obvious that $\mathrm{DPPH}$ assays varied to a great extent, ranging from 0.85 to $43.43 \mathrm{mM}$ $\mathrm{AAE} / \mathrm{g}$ among the extract accessions when the temperature rose from $160^{\circ} \mathrm{C}$ to $220^{\circ} \mathrm{C}$. In other words, DPPH radicalscavenging activities of extracts significantly increased $(p<0.05)$ as the temperature elevated. The results indicated that SWE plays a positive role on promoting the quantity of antioxidant metabolites in the obtained extracts and advancing radical-scavenging activity. Moreover, it could be attributed to the hydrolysis of glycoside bonds of phenolic compounds, thus increasing the number of phenolic hydroxyl groups and consequently the antioxidant activity of the extracts, taking into account TPC and TFC content in the extracts.

3.2.2. Total Antioxidant Activity Using ABTS. Since the characteristic absorption spectrum of ABTS cation radical can be determined at $414,645,734$, and $815 \mathrm{~nm}[30,31]$ because of the presence of antioxidants [32], common organic radical cation $\left(\mathrm{ABTS}^{+}\right)$assay is one of the most widely applied methods to assess antioxidant activity [33]. In addition, other reports indicated that ABTS radical-scavenging activity is more of accuracy, sensitivity, and robustness for screening single ingredient and other complex antioxidant mixtures such as plant extracts, beverages, and biological fluids [34].

Eight extracts at various temperature levels were measured and compared for their free radical-scavenging activities against ABTS radicals, and the results of the scavenging ability of SWE extracts on ABTS free radicals are shown in Figure 3. Apparently, all the extracts reduced the absorbance at $734 \mathrm{~nm}$, and the concentration of the extracts was directly proportional to the reduction. In the ABTS radical-scavenging assay, noteworthy differences among values of all the extracts were found $(p<0.05)$. As the control group, ascorbic acid at a concentration of 0.3125$10 \mathrm{mg} / \mathrm{mL}$ was also available to produce excellent inhibition of ABTS radicals. To be more specific, levels of ABTS radicalscavenging activities followed a descending order of $220^{\circ} \mathrm{C}>230^{\circ} \mathrm{C}>210^{\circ} \mathrm{C}>200^{\circ} \mathrm{C}>190^{\circ} \mathrm{C}>180^{\circ} \mathrm{C}>170^{\circ} \mathrm{C}$ and $160^{\circ} \mathrm{C}$ with values of $77.06 \%, 72.94 \%, 72.13 \%, 61.83 \%$, $51.57 \%, 37.27 \%, 19.10 \%$, and $15.01 \%$ at the initial concentration of $0.3125 \mathrm{mg} / \mathrm{mL}$, respectively. When the concentration rose to $2.5 \mathrm{mg} / \mathrm{mL}$, almost all the samples were equal to the effect produced by ascorbic acid at the same concentration, except for the sample processed at $160^{\circ} \mathrm{C}$. Another result should be pointed out that the effect of scavenging capacity on ABTS radicals was as significant as that of ascorbic acid when the concentration of test solution was greater than $5 \mathrm{mg} / \mathrm{mL}$, which indicated that there was no difference on ABTS radical-scavenging activity between aqueous extracts and ascorbic acid at a relatively higher concentration.

Also, it should be noted that DPPH and ABTS assays were conducted in ethanol and water media, respectively [35]. From a mechanistic perspective, the DPPH radicalscavenging assay emphasizes the capacity of the extract

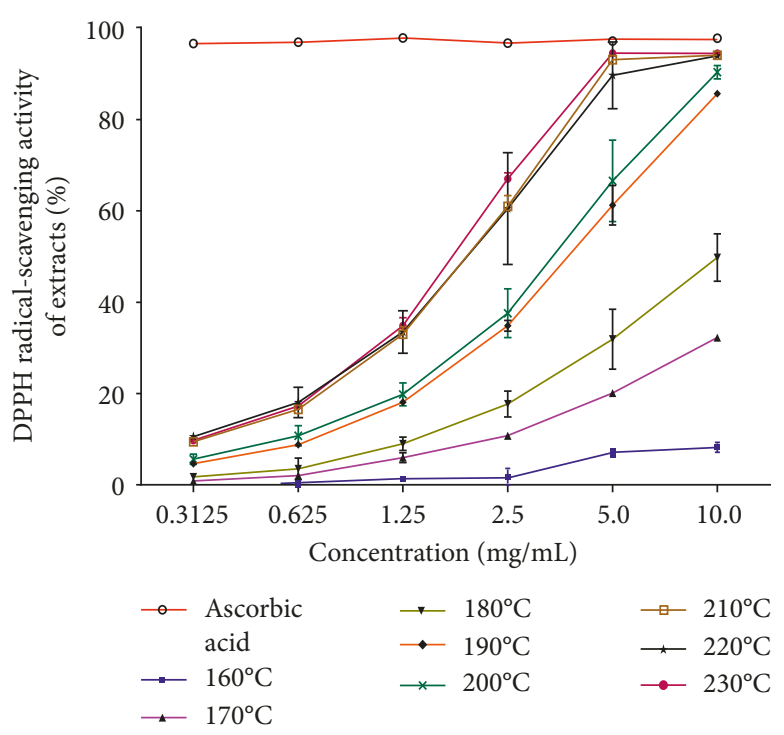

FIGURE 2: DPPH radical-scavenging assays of different aqueous extracts from okara by SWE and standard antioxidant (ascorbic acid). Data were expressed as mean \pm standard deviation of triplicate samples.

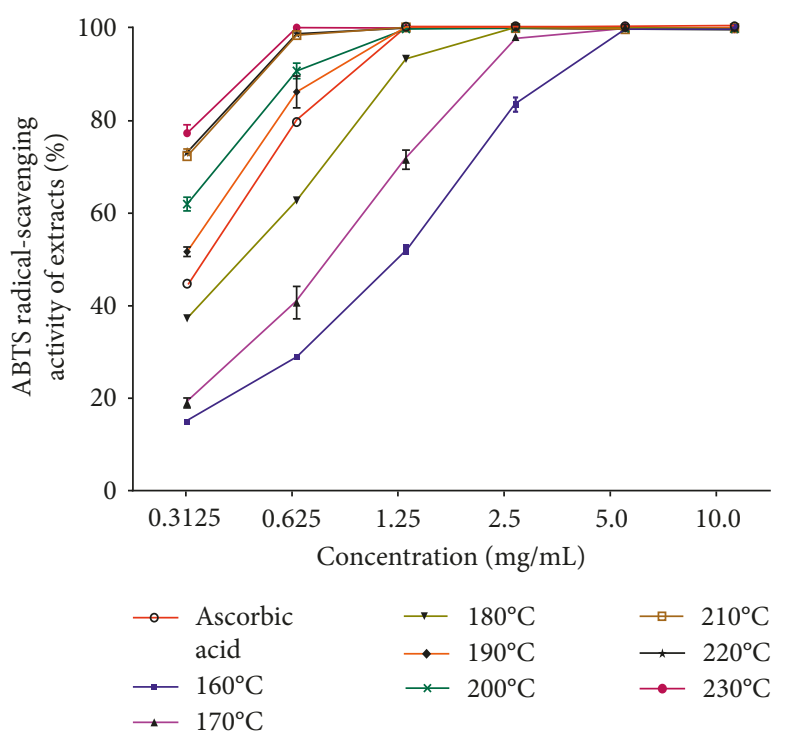

FIGURE 3: ABTS radical-scavenging assays of different aqueous extracts from okara by SWE and standard antioxidant (ascorbic acid). Data were expressed as mean \pm standard deviation of triplicate samples.

transferring electrons or hydrogen atoms, while the ABTS radical-scavenging activity could reflect the hydrogen donating and the chain-breaking capacity of the extract [36]. The order of ABTS radical-scavenging activity was consistent with that of the DPPH radical, suggesting thermal treatment had decisive effects on scavenging radicals dissolved in organic or aqueous solvent, to some extent.

3.3. Correlations among Constituents and Antioxidant Activities. In order to evaluate the suitability and reliability 
TABLE 2: Correlation coefficients between constituents and antioxidant activities of okara extracts by SWE.

\begin{tabular}{|c|c|c|c|c|c|c|c|}
\hline$R\left(R^{2}\right)$ & TOC & Total sugar & Polysaccharides & TPC & TFC & DPPH & $\overline{\mathrm{ABTS}}$ \\
\hline TOC & 1 & - & - & - & - & - & - \\
\hline Total sugar & $0.899(0.808)^{* *}$ & 1 & - & - & - & - & - \\
\hline Polysaccharides & $0.815(0.664)^{*}$ & $0.952(0.906)^{* *}$ & 1 & - & - & - & - \\
\hline TPC & $-0.878(0.771)^{* *}$ & $-0.967(0.935)^{* *}$ & $-0.959(0.920)^{* *}$ & 1 & - & - & - \\
\hline TFC & $-0.821(0.674)^{*}$ & $-0.968(0.937)^{* *}$ & $-0.897(0.805)^{* *}$ & $0.959(0.920)^{* *}$ & 1 & - & - \\
\hline $\mathrm{DPPH}$ & $-0.857(0.734)^{* *}$ & $-0.981(0.962)^{* *}$ & $-0.914(0.835)^{* *}$ & $0.962(0.925)^{* *}$ & $0.982(0.945)^{* *}$ & 1 & - \\
\hline ABTS & $-0.872(0.760)^{* *}$ & $-0.993(0.986)^{* *}$ & $-0.954(0.910)^{* *}$ & $0.980(0.960)^{* *}$ & $0.973(0.947)^{* *}$ & $0.988(0.976)^{* *}$ & 1 \\
\hline
\end{tabular}

$R$ : correlation coefficient. $R^{2}$ : coefficient of correlation. ${ }^{*}$ Significant at $p<0.05 .{ }^{* *}$ Significant at $p<0.01$.

of the antioxidant assay for measurement of total antioxidant activity of extracts from okara by SWE, Pearson correlation coefficients between the antioxidant capacities (DPPH and ABTS), total organic carbon, total sugar, polysaccharides, total phenolic content, and total flavonoid content for all extracts prepared under different extraction temperatures were calculated and the results are shown in Table 2. According to the results of the present study, significant correlations $(p<0.05)$ were detected in all cases, which revealed that values of antioxidant activity determined by two different methods were comparable and reliable.

TOC showed strongly linear relationship with total sugar $\left(R=0.899 ; \quad R^{2}=0.808, \quad p<0.01\right)$, and polysaccharides $\left(R=0.815 ; R^{2}=0.664, p<0.05\right)$, which is in accordance with the fact that carbon element is essential in these two compounds. It should be noted that TOC, total sugar, and polysaccharides were negatively correlated with two selected in vitro assays, suggesting there was no direct relation between the three aforementioned carbohydrates and antioxidant abilities under these subcritical water conditions. Too much exposure to elevated temperatures contributed to their degradation and inactivation. The correlation coefficient for DPPH and ABTS assay $\left(R=0.988 ; R^{2}=0.976\right.$, $p<0.01)$ indicated that the values of antioxidant activities assayed by these two different methods were significantly correlated, associating with spectrophotometry-based assay methods and elimination ability of the radical cation [37].

Phenolic compounds in extracts, like other antioxidative compounds, are believed to account for a major portion of the antioxidant activity in many plants due to interaction with free radicals by acting as electron donor of hydrogen atoms. Measurements of the scavenging effects of DPPH and ABTS radicals showed that radical-scavenging capacity increased with increase in TPC. Apparently, TPC exhibited a strong correlation with both DPPH $\left(R=0.962 ; R^{2}=0.925\right.$, $p<0.01)$ and ABTS $\left(R=0.980 ; R^{2}=0.960, p<0.01\right)$. Consistently, as main ingredients of TPC $\left(R=0.959 ; R^{2}=0.920\right.$, $p<0.01)$, TFC also has closed connections with both DPPH $\left(R=0.982 ; \quad R^{2}=0.945, \quad p<0.01\right)$ and ABTS $(R=0.973$; $\left.R^{2}=0.947, p<0.01\right)$. The high correlations obtained in this work could suggest that the antioxidant activities of these extracts are resulted from phenolic compounds which contribute to the DPPH and ABTS scavenging activities. All these results differ from previous studies on Amaranthus mantegazzianus [38]. Three factors may bring about the differences between the results of this study and other studies: (1) the difference in plant matrix; (2) the method and conditions of extraction (temperature, time, and solvents) led to differences in compositions and antioxidant activities; (3) the difference of phenolic structures like possessing a higher number of hydroxyl groups [39]. It is worth noting that there must be some other soluble compounds existing in the extracts, like proteins, peptides, and pigments, might be also responsible for the antioxidant activity partly [40].

\section{Conclusions}

Thermal processing had significant effects on the compositions and antioxidant activities on okara extracts in this study. Specifically, TOC, total sugar, and polysaccharides in extracts decreased under elevated temperature due to some reactions like pyrolysis and gasification. The highest yields of TPC and TFC were observed in the extract obtained as extraction temperature was $220^{\circ} \mathrm{C}$ with the other two fixed parameters (residence time of $10 \mathrm{~min}$ and liquid-solid ratio of $30 \mathrm{~mL} / \mathrm{g}$ ). Among the various aqueous extracts, all aqueous extracts showed high antioxidant activity, which indicated SWE played important roles in the increase of the antioxidant capacities of okara extracts on DPPH scavenging activity and ABTS assay. According to correlation comparisons, the total phenolic contents of the extracts were coherent with the antioxidant activities of the extracts, pending further analysis of their specific composition to explain the underlying mechanism. This finding could be useful to the disposal processing of okara by-products in the food industry.

\section{Data Availability}

The data used to support the findings of this study are available from the corresponding author upon request.

\section{Conflicts of Interest}

The authors declare that they have no conflicts of interest.

\section{References}

[1] Y. Yao and G. Ren, "Effect of thermal treatment on phenolic composition and antioxidant activities of two celery cultivars," LWT-Food Science and Technology, vol. 44, no. 1, pp. 181-185, 2011.

[2] B. D. Craft, A. L. Kerrihard, R. Amarowicz, and R. B. Pegg, "Phenol-based antioxidants and the in vitro methods used for 
their assessment," Comprehensive Reviews in Food Science and Food Safety, vol. 11, no. 2, pp. 148-173, 2012.

[3] O. Pourali, F. S. Asghari, and H. Yoshida, "Sub-critical water treatment of rice bran to produce valuable materials," Food Chemistry, vol. 115, no. 1, pp. 1-7, 2009.

[4] R. L. Holliday, B. Y. Jong, and J. W. Kolis, "Organic synthesis in subcritical water: oxidation of alkyl aromatics," Journal of Supercritical Fluids, vol. 12, no. 3, pp. 255-260, 1998.

[5] A. Kruse and E. Dinjus, "Hot compressed water as reaction medium and reactant: properties and synthesis reactions," Journal of Supercritical Fluids, vol. 39, no. 3, pp. 362-380, 2007.

[6] M. Plaza and C. Turner, "Pressurized hot water extraction of bioactives," TrAC Trends in Analytical Chemistry, vol. 71, pp. 39-54, 2015.

[7] G. Joana Gil-Chávez, J. A. Villa, J. Fernando Ayala-Zavala et al., "Technologies for extraction and production of bioactive compounds to be used as nutraceuticals and food ingredients: an overview," Comprehensive Reviews in Food Science and Food Safety, vol. 12, no. 1, pp. 5-23, 2013.

[8] K. Sharma, E. Y. Ko, A. D. Assefa et al., "Temperaturedependent studies on the total phenolics, flavonoids, antioxidant activities, and sugar content in six onion varieties," Journal of Food and Drug Analysis, vol. 23, no. 2, pp. 243-252, 2015.

[9] H. Sun, Extraction, Identification and Antioxidant Activities of Polysaccharides and Phenolic Compounds from Okara Using Subcritical Water Technology, University of Tsukuba, Tsukuba, Japan, 2016

[10] M. Mecozzi, "Estimation of total carbohydrate amount in environmental samples by the phenol-sulphuric acid method assisted by multivariate calibration," Chemometrics and Intelligent Laboratory Systems, vol. 79, no. 1-2, pp. 84-90, 2005.

[11] S. Min, Y. Yingnan, G. Di, Y. Zhang, and Z. Zhang, "Bioactivity of the crude polysaccharides from fermented soybean curd residue by Flammulina velutipes," Carbohydrate Polymers, vol. 89, no. 4, pp. 1268-1276, 2012.

[12] C.-W. Ma, M. Feng, X. Zhai et al., "Optimization for the extraction of polysaccharides from Ganoderma lucidum and their antioxidant and antiproliferative activities," Journal of the Taiwan Institute of Chemical Engineers, vol. 44, no. 6, pp. 886-894, 2013.

[13] L. Shuhong, S. Yaxin, Z. Dan, Y. Yang, Z. Lei, and Z. Zhang, "Optimization of fermentation conditions for crude polysaccharides by Morchella esculenta using soybean curd residue," Industrial Crops and Products, vol. 50, pp. 666-672, 2013.

[14] M. G. Miguel, S. Nunes, S. A. Dandlen, A. M. Cavaco, and M. D. Antunes, "Phenols and antioxidant activity of hydroalcoholic extracts of propolis from Algarve, South of Portugal," Food and Chemical Toxicology, vol. 48, no. 12, pp. 3418-3423, 2010.

[15] J. Zhishen, T. Mengcheng, and W. Jianming, "The determination of flavonoid contents in mulberry and their scavenging effects on superoxide radicals," Food Chemistry, vol. 64, no. 4, pp. 555-559, 1999.

[16] R. Re, N. Pellegrini, A. Proteggente, A. Pannala, M. Yang, and C. Rice-Evans, "Antioxidant activity applying an improved ABTS radical cation decolorization assay," Free Radical Biology and Medicine, vol. 26, no. 9-10, pp. 1231-1237, 1999.

[17] A. Moure, J. M. Cruz, D. Franco et al., "Natural antioxidants from residual sources," Food Chemistry, vol. 72, no. 2, pp. 145-171, 2001.
[18] C. D. Stalikas, "Extraction, separation, and detection methods for phenolic acids and flavonoids," Journal of Separation Science, vol. 30, no. 18, pp. 3268-3295, 2007.

[19] Z. Zhenya and S. Hongyi, "Optimization of okara polysaccharides extraction using subcritical water technology and its antioxidant activity," in Proceedings of the 5th International Conference of Bionic Engineering, Ningbo, China, June 2016.

[20] C. Corradini, A. Cavazza, and C. Bignardi, "High-performance anion-exchange chromatography coupled with pulsed electrochemical detection as a powerful tool to evaluate carbohydrates of food interest: principles and applications," International Journal of Carbohydrate Chemistry, vol. 2012, Article ID 487564, 13 pages, 2012.

[21] J. Mulero, G. Martínez, J. Oliva et al., "Phenolic compounds and antioxidant activity of red wine made from grapes treated with different fungicides," Food Chemistry, vol. 180, pp. 25-31, 2015.

[22] A. Wojdyło, J. Oszmiański, and R. Czemerys, "Antioxidant activity and phenolic compounds in 32 selected herbs," Food Chemistry, vol. 105, no. 3, pp. 940-949, 2007.

[23] L. Priecina and D. Karlina, "Total polyphenol, flavonoid content and antiradical activity of celery, dill, parsley, onion and garlic dried in conventional and microwave-vacuum dryers," IPCBEE, vol. 53, pp. 107-112, 2013.

[24] M. Hassas-Roudsari, P. R. Chang, R. B. Pegg, and R. Tyler, "Antioxidant capacity of bioactives extracted from canola meal by subcritical water, ethanolic and hot water extraction," Food Chemistry, vol. 114, no. 2, pp. 717-726, 2009.

[25] K. B. Pandey and S. I. Rizvi, "Plant polyphenols as dietary antioxidants in human health and disease," Oxidative Medicine and Cellular Longevity, vol. 2, no. 5, pp. 270-278, 2009.

[26] K. Ioku, Y. Aoyama, A. Tokuno, J. Terao, N. Nakatani, and Y. Takei, "Various cooking methods and the flavonoid content in onion," Journal of Nutritional Science and Vitaminology, vol. 47, no. 1, pp. 78-83, 2001.

[27] C. Manach, A. Scalbert, C. Morand, C. Rémésy, and L. Jiménez, "Polyphenols: food sources and bioavailability," American Journal of Clinical Nutrition, vol. 79, no. 5, pp. 727-747, 2004.

[28] J. R. Soare, T. C. Dinis, A. P. Cunha, and L. Almeida, "Antioxidant activities of some extracts of Thymus zygis," Free Radical Research, vol. 26, no. 5, pp. 469-478, 1997.

[29] Y.-C. Hseu, W.-H. Chang, C.-S. Chen et al., "Antioxidant activities of Toona Sinensis leaves extracts using different antioxidant models," Food and Chemical Toxicology, vol. 46, no. 1, pp. 105-114, 2008.

[30] M. Arnao, M. Acosta, J. Del Rio, and F. García-Cánovas, "Inactivation of peroxidase by hydrogen peroxide and its protection by a reductant agent," Biochimica et Biophysica Acta (BBA)-Protein Structure and Molecular Enzymology, vol. 1038, no. 1, pp. 85-89, 1990.

[31] N. J. Miller, C. Rice-Evans, M. J. Davies, V. Gopinathan, and A. Milner, "A novel method for measuring antioxidant capacity and its application to monitoring the antioxidant status in premature neonates," Clinical science, vol. 84, no. 4, pp. 407-412, 1993.

[32] D. Villaño, M. Fernández-Pachón, A. Troncoso, and M. C. García-Parrilla, "The antioxidant activity of wines determined by the ABTS+ method: influence of sample dilution and time," Talanta, vol. 64, no. 2, pp. 501-509, 2004.

[33] S. Rawat, I. D. Bhatt, and R. S. Rawal, "Total phenolic compounds and antioxidant potential of Hedychium spicatum Buch. Ham. ex D. Don in west Himalaya, India," Journal 
of Food Composition and Analysis, vol. 24, no. 4-5, pp. 574579, 2011.

[34] P. Govindan and S. Muthukrishnan, "Evaluation of total phenolic content and free radical scavenging activity of Boerhavia erecta," Journal of Acute Medicine, vol. 3, no. 3, pp. 103-109, 2013.

[35] K.-X. Zhu, C.-X. Lian, X.-N. Guo, W. Peng, and H.-M. Zhou, "Antioxidant activities and total phenolic contents of various extracts from defatted wheat germ," Food Chemistry, vol. 126, no. 3, pp. 1122-1126, 2011.

[36] J. Pérez-Jiménez, S. Arranz, M. Tabernero et al., "Updated methodology to determine antioxidant capacity in plant foods, oils and beverages: extraction, measurement and expression of results," Food Research International, vol. 41, no. 3, pp. 274-285, 2008.

[37] E. Skotti, E. Anastasaki, G. Kanellou, M. Polissiou, and P. A. Tarantilis, "Total phenolic content, antioxidant activity and toxicity of aqueous extracts from selected Greek medicinal and aromatic plants," Industrial Crops and Products, vol. 53, pp. 46-54, 2014.

[38] V. Castel, O. Andrich, F. M. Netto, L. G. Santiago, and C. R. Carrara, "Total phenolic content and antioxidant activity of different streams resulting from pilot-plant processes to obtain Amaranthus mantegazzianus protein concentrates," Journal of Food Engineering, vol. 122, pp. 62-67, 2014.

[39] Q. D. Do, A. E. Angkawijaya, P. L. Tran-Nguyen et al., "Effect of extraction solvent on total phenol content, total flavonoid content, and antioxidant activity of Limnophila aromatica," journal of food and drug analysis, vol. 22, no. 3, pp. 296-302, 2014.

[40] R. L. Prior, X. Wu, and K. Schaich, "Standardized methods for the determination of antioxidant capacity and phenolics in foods and dietary supplements," Journal of Agricultural and Food Chemistry, vol. 53, no. 10, pp. 4290-4302, 2005. 

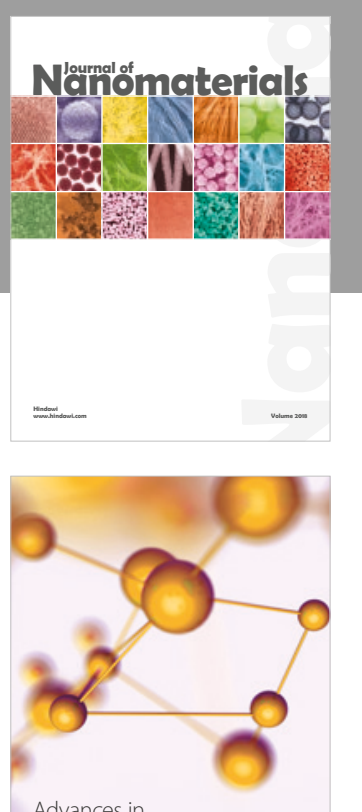

Physical Chemistry
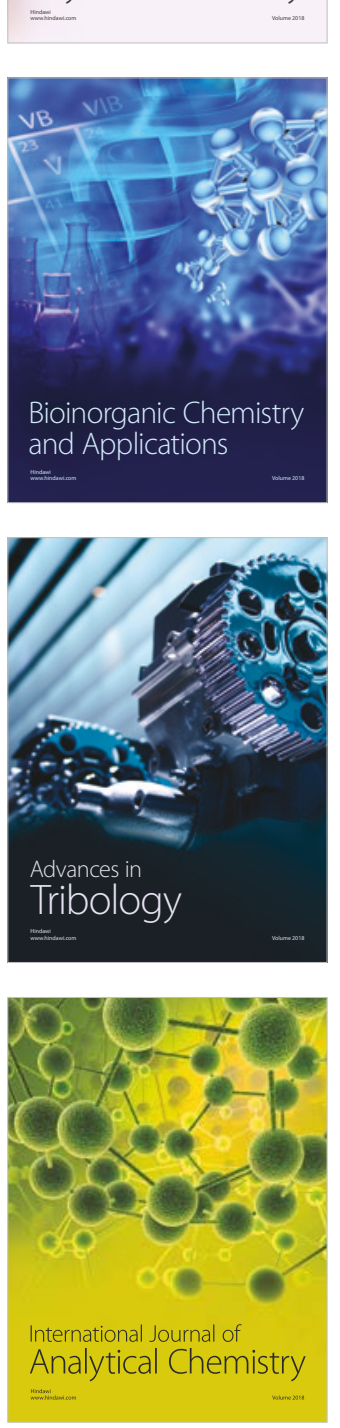

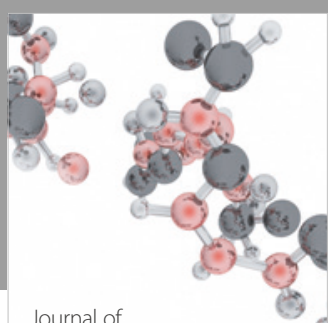

Analytical Methods

in Chemistry

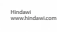

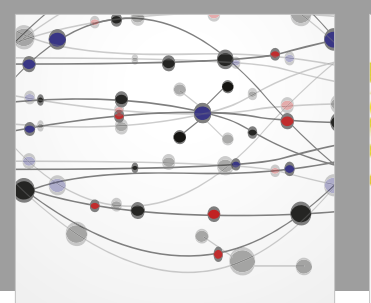

The Scientific World Journal

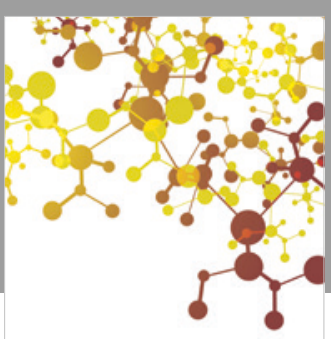

Journal of

Applied Chemistry
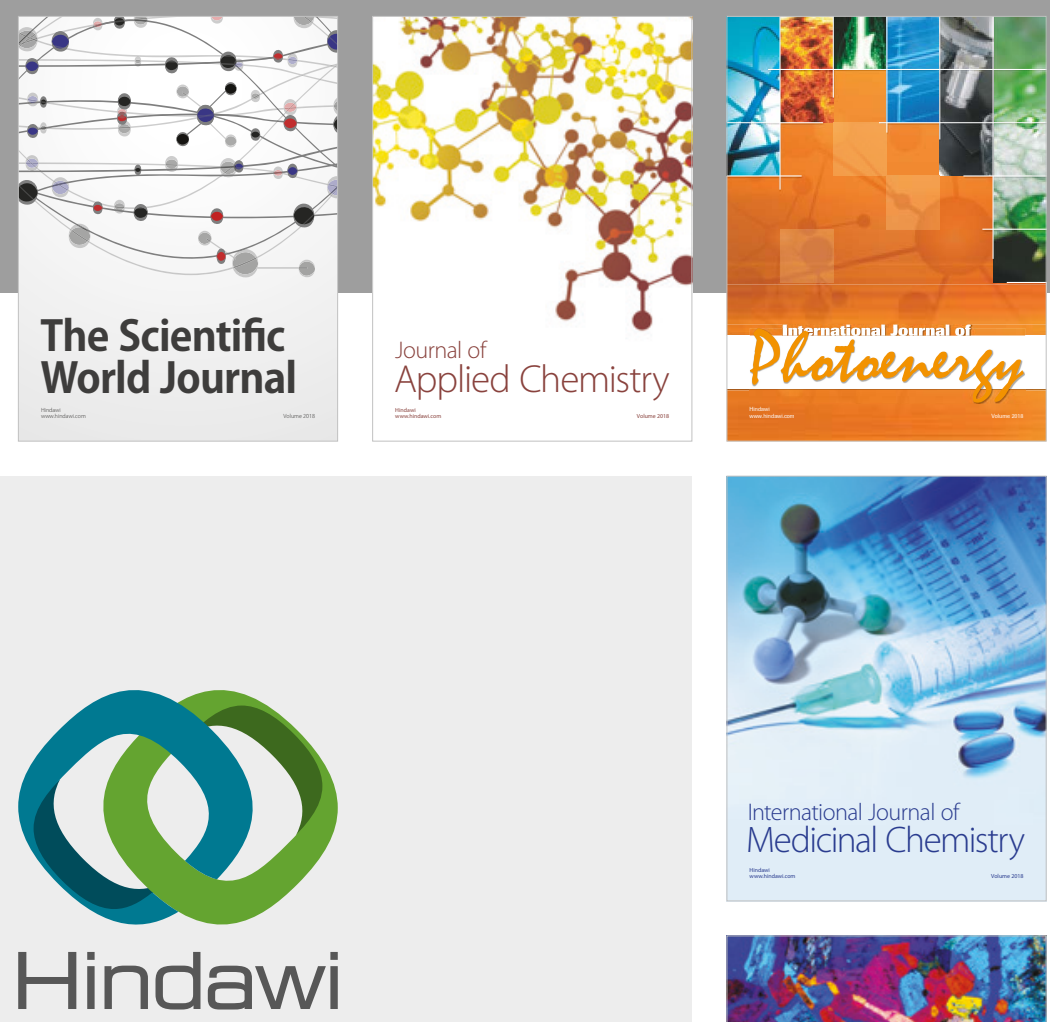

Submit your manuscripts at

www.hindawi.com
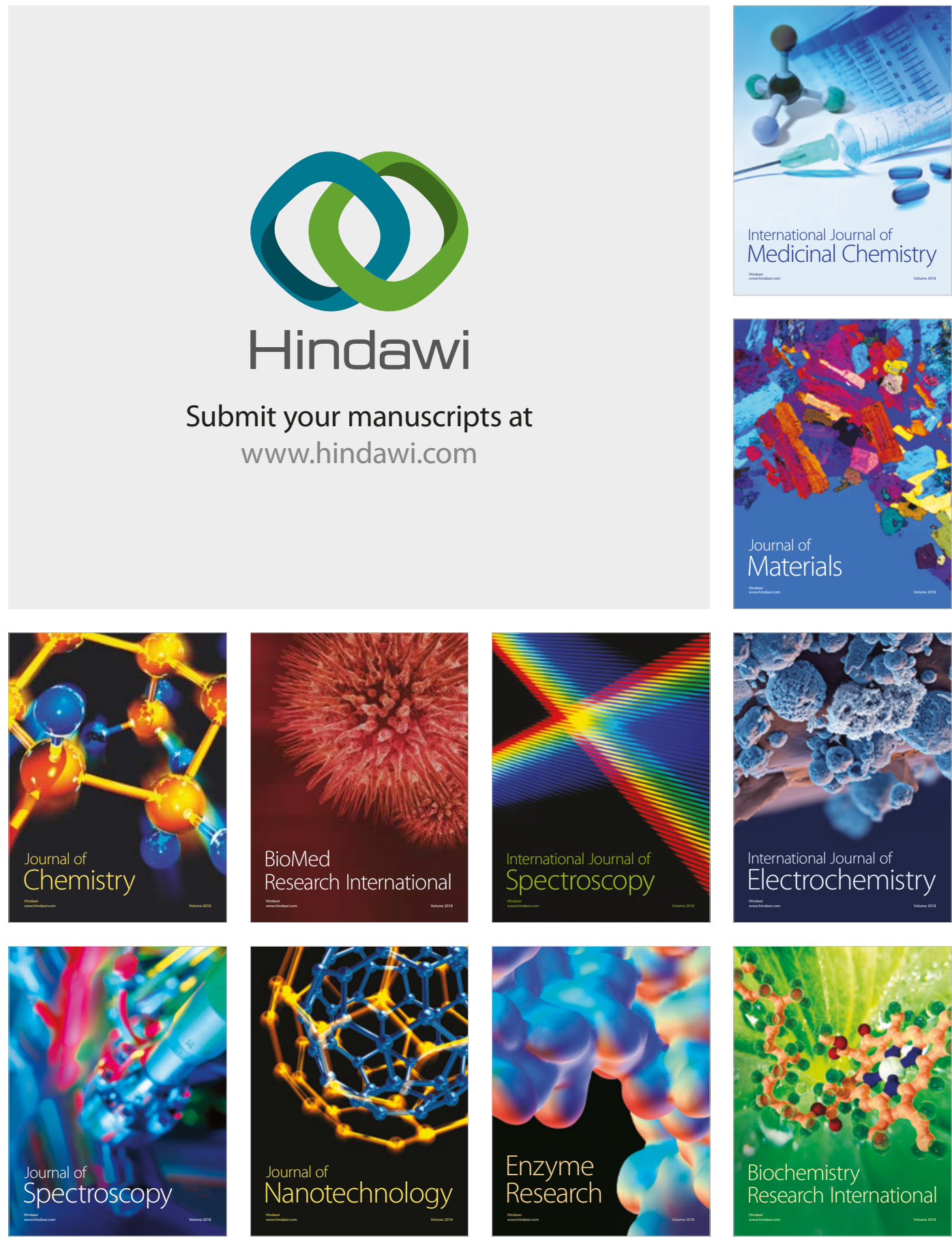
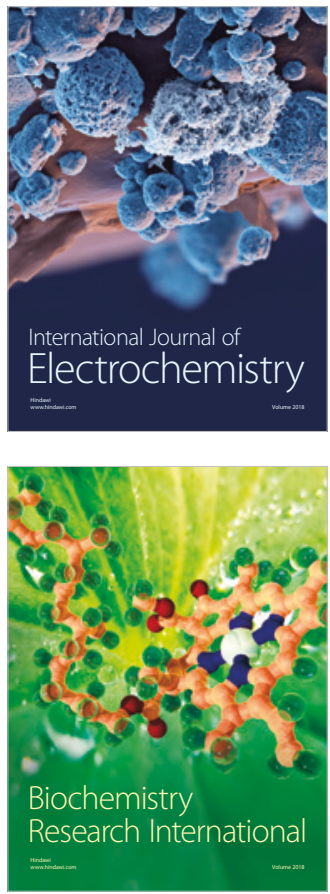